\title{
Skin Neoplasm
}

National Cancer Institute

\section{Source}

National Cancer Institute. Skin Neoplasm. NCI Thesaurus. Code C3372.

A benign or malignant tumor involving the skin. Representative examples of benign skin neoplasms include the benign melanocytic skin nevus, acanthoma, sebaceous adenoma, sweat gland adenoma, lipoma, hemangioma, fibroma, and benign fibrous histiocytoma. Representative examples of malignant skin neoplasms include basal cell carcinoma, squamous cell carcinoma, melanoma, and Kaposi sarcoma. 